\title{
Low-pressure membrane technology for potable water filtration: true costs
}

S.J. Judd* and I. Carra, Cranfield Water Science Institute, Cranfield University MK43 0AL

*corresponding author, s.j.judd@cranfield.ac.uk

\section{Abstract}

The overall cost, expressed as the present value (PV), of the construction and operation of lowpressure membrane filtration of inland water for potable water supply has been determined for membrane installations across the UK. The analysis was based on 15 full-scale installations installed with hollow fibre and capillary tube polymeric membranes, for which cost and related data were available. The analysis encompassed labour, in addition to energy, chemicals and critical component replacement. PV data were presented as functions of flow capacity (i.e. as cost curves), delineated as capital (CAPEX), operating (OPEX) and total PV normalised against flow rate (PV') the CAPEX excluding the site-specific civil engineering costs.

Captured CAPEX data revealed these to be lower than those previously reported, and with a reduced economy of scale. The OPEX PV exceeded the CAPEX by a factor of 3-6 based on a 20-year life cycle, the difference increasing with decreasing flow capacities. Costs associated with unplanned (or "reactive") maintenance, partly associated with the repair of breached membranes and/or permeability recovery following membrane clogging, were found to make up around half the labour costs. Labour costs as a proportion of the flow increased with decreasing flow, exceeding the CAPEX at flows below $30,000 \mathrm{~m}^{3} / \mathrm{d}$.

Outcomes indicate labour costs associated with process upsets to contribute significantly to the overall cost of the installation over its life cycle, particularly at flows below $\sim 30,000 \mathrm{~m}^{3} / \mathrm{d} \mathrm{A}$ clear 
trade-off exists between supplementary capital investment to allay process upsets and the operational costs associated with such events.

Keywords: Low-pressure membranes; cost; present value; labour; process upset

\section{Introduction}

Whilst there are many elements to process selection in water and wastewater treatment, cost remains the most important governing factor. A number of cost analyses have been conducted within the subject area of low-pressure membrane filtration (i.e. ultrafiltration, UF or microfiltration, MF) technology for water treatment over the past 10 years-or-so. These have tended to concentrate on particular physical or chemical facets of the treatment technology, employing cost analysis for optimisation purposes. Recent examples of such topics (Table 1) include pre-treatment using powdered activated carbon (PAC) (Campinas et al, 2021) or coagulant (Arhin et al, 2019), maintenance optimisation with reference backwashing (Bai et al, 2020) or chemical cleaning (Yoo et al, 2018), module design (Lee et al, 2020), and membrane material - and in particular the cost comparison of ceramic and polymeric membranes (Hurvitz et al, 2018; Park et al, 2015; Guerra and Pellegrino, 2012, 2013).

Whilst these papers have all offered insight into relative costs, analyses have to an extent necessarily been constrained in their scope. Many studies (Hurvitz et al, 2018; Yoo et al, 2018; Zheng et al, 2011) have been limited to operating expenditure (OPEX), based largely on a consideration of energy and consumables. Some of the studies which have encompassed capital costs have been based on a single flow capacity (Bai et al, 2020; Park et al, 2014; Guerra and Pellegrino, 2012, 2013). Correlations reported in these studies have been generated from either outputs from trials conducted at bench or pilot scale (Guerra and Pellegrino, 2012) or a single full-scale reference installation (Bai et al, 2020). The few recent studies that have provided correlations of total cost with flow (Campinas et al, 2021; 
Arhin et al, 2019) have been aimed specifically at optimising flux and upstream dosing with coagulant of PAC. As with most other studies, these have been focused primarily on fouling suppression to optimise membrane permeability.

Table 1. Reported cost studies, low-pressure membranes

\begin{tabular}{|c|c|c|c|c|c|c|c|}
\hline Authors & Year & $\begin{array}{l}\text { Scale } \\
\text { or } A_{m}\end{array}$ & Feed & $\begin{array}{c}\text { Membrane } \\
\text { state }\end{array}$ & $\begin{array}{c}\text { Key } \\
\text { variable(s) }\end{array}$ & $\begin{array}{r}\text { Flow } \\
000 \mathrm{~s} \\
\mathrm{~m}^{3} / \mathrm{d}\end{array}$ & Correlations produced \\
\hline $\begin{array}{l}\text { Guerra \& } \\
\text { Pellegrino }\end{array}$ & 2013 & $0.15-0.2 \mathrm{~m}^{2}$ & Bentonite & Virgin & $\mathrm{Pe}$ & 18.9 & $\begin{array}{l}\text { Impact of Pe on cost for } \\
\text { different membrane materials }\end{array}$ \\
\hline Park et al & 2014 & $\begin{array}{c}1,000-30,000 \\
\mathrm{~m}^{3} / \mathrm{d}\end{array}$ & $\begin{array}{l}\text { Raw } \\
\text { water }\end{array}$ & Aged & Material & 30 & $\begin{array}{l}\text { LCC vs membrane cost, } \\
\text { polymeric vs ceramic based } \\
\text { on full-scale plant }\end{array}$ \\
\hline $\begin{array}{l}\text { Hurwitz } \\
\text { et al }\end{array}$ & 2018 & $2.5-3 \mathrm{~m}^{2}$ & $\begin{array}{l}\text { Raw } \\
\text { water }\end{array}$ & Aged & None & - & $\begin{array}{l}\text { OPEX only (from specific } \\
\text { energy consumption) }\end{array}$ \\
\hline Yoo et al & 2018 & $72 \mathrm{~m}^{2}$ & $\begin{array}{l}\text { Raw } \\
\text { water }\end{array}$ & Virgin & Flux & - & OPEX only \\
\hline $\begin{array}{l}\text { Arhin et } \\
\text { al }\end{array}$ & 2019 & $4.5 \mathrm{~m}^{2}$ & $\begin{array}{l}\text { Raw } \\
\text { Water }\end{array}$ & Virgin & $\begin{array}{l}\text { PACl dose } \\
\text { flux }\end{array}$ & $5-100$ & $\begin{array}{l}\text { Cost constituent values vs } \\
\text { flow }\end{array}$ \\
\hline Bai et al & 2020 & Full & $\begin{array}{l}\text { 2ndary } \\
\text { Ww }\end{array}$ & Aged & - & 30 & $\begin{array}{l}\text { Cost per year for different } \\
\text { service life values }\end{array}$ \\
\hline Lee et al & 2020 & Single-house & $\begin{array}{l}\text { Kaolin, } \\
\text { Ww }\end{array}$ & Virgin & Technology & $<0.5$ & $\begin{array}{l}\text { Cost comparison for different } \\
\text { household water systems }\end{array}$ \\
\hline $\begin{array}{l}\text { Campinas } \\
\text { et al }\end{array}$ & 2021 & $0.75 \mathrm{~m}^{2}$ & $\begin{array}{l}\text { Raw } \\
\text { water }\end{array}$ & Virgin & $\begin{array}{l}\text { PAC dose, } \\
\text { flux }\end{array}$ & $0-150$ & $\begin{array}{l}\text { CAPEX \& OPEX vs flow at } \\
\text { various membrane } \\
\text { permeabilities }\end{array}$ \\
\hline
\end{tabular}

$A_{m}$ membrane area; Pe Peclet number (flux/mass transfer coefficient); Ww wastewater

"Scale" refers to scale of experimental study; "Flow" refers to the flow or flow range modelled.

In practice, it is doubtful that fouling represents the most significant factor in terms of overall cost of low-pressure membrane technology (Judd, 2017). Whilst it is immutably the case that a higher sustainable flux reduces CAPEX due to the decreased membrane area requirement and OPEX from the corresponding membrane replacement, fouling represents only one of three factors impacting of cost, the other two being (a) integrity monitoring and repair, and (b) clogging. Integrity refers to the condition of the membrane with respect to damage and possible breaching by pathogens (Lee et al, 2019; Ferrer et al, 2015); clogging is the agglomeration of solids within membrane channels, and is most often associated with membrane bioreactors (Buzatu et al, 2018; Zsirai et al, 2012). Both phenomena incur additional labour effort which ultimately adds to the OPEX. 
It is also the case that estimation of CAPEX is challenged by the paucity of available data, coupled with considerable discrepancies between the few data sets available. The recent analysis of Arhin et al (2019) made use of the correlation of Guo et al (2014) for UF installations:

$$
\log (\mathrm{CAPEX}, \$)=1.003\left(\log \left(Q, \mathrm{~m}^{3} / \mathrm{d}\right)\right)^{0.830}+3.832
$$

Whilst this correlation was generated from data pertaining to actual installations, it is based on only six data points - only four of which refer to flows above $100 \mathrm{~m}^{3} / \mathrm{d}$. According to Equation 1, a 10,000 $\mathrm{m}^{3} / \mathrm{d}$ plant would have cost around $\$ 10 \mathrm{~m}$ in 2013 , equating to $\sim £ 7 \mathrm{~m}$ at that time and $\sim £ 8 \mathrm{~m}$ today.

The recently reported work of Campinas et al (2021), based on a ceramic membrane, is more exhaustive in determining CAPEX. The authors account for the cost of each component through employing a power law function in terms of the installed membrane area $A$ :

$$
\mathrm{CAPEX}=m A_{m}{ }^{n}
$$

where $m$ and $n$ are empirical constants dependent on the CAPEX component. $A_{m}$ can then be correlated with $Q$ based on the assumption of a constant net flux.

The authors' CAPEX equation exponent values for ancillary equipment (itemised as "membranes", "pipes and valves", "instruments and controls", "tanks and frames", and “miscellaneous”) were taken from the report of Guerra and Pellegrino (2013), which was also specific to ceramic membranes. Guerra and Pellegrino in turn cited Sethi (1997) as the source of their exponent values, where Sethi's correlations for the "pipes and valves" and "instruments and controls" components were based on those reported by Gumerman et al (1979), whereas the source of the "tanks and frames" cost 
components was Peters and Kimmerhaus (1991). These cost function coefficient $m$ and exponent $n$ values (Table 2) from Equation 2 therefore date back 30-40 years.

Table 2. Values of empirical constants in Equation 2 (Campinas et al, 2021)

\begin{tabular}{l|ccl}
\hline CAPEX component & $m$ & $n$ & Source \\
\hline Membranes cost & 756 & 0.97 & Guerra and Pellegrino, 2012 \\
Pipes \& valves cost & 5313 & 0.42 & Gumerman et al, 1979 \\
Instruments \& controls & 1296 & 0.66 & Gumerman et al, 1979 \\
Tanks \& frames & 2732 & 0.53 & Peters and Kimmerhaus, 1991 \\
Miscellaneous & 7052 & 0.57 & Guerra and Pellegrino, 2012 \\
\hline
\end{tabular}

The use of a ceramic membrane means that the membrane contribution to the CAPEX is substantially higher than that from polymeric membranes, notwithstanding the higher operational flux provide by ceramic materials. The OPEX is conversely lower due to a combination of the increased membrane net permeability and the obviation of membrane repair associated with integrity failure. Combining cost functions from processes with substantially different functional attributes thus becomes problematic.

Although only approximate representations of CAPEX with flow capacity are needed for the purposes of calculating relative cost benefits from altered operational practices, as in the analyses of Arhin et al (2019) and Campinas et al (2021), it remains the case that there are few accurate, up-to-date cost curves for low-pressure potable water membrane technologies. The approach adopted by Campinas et al (2021) is rigorous in including all contributions to the CAPEX as separate functions, but the validity of cost curve exponent values across different applications, dates and geographical regions is questionable. It is clearly preferable to obtain data directly relevant to the region of interest, and pertaining to as narrow time-frame as practically possible. Moreover, the impact of labour costs needs to be taken into account, since this aspect is often either overlooked or else based on simple approximations (such as those presented by Mulder et al (2015) and subsequently used by Campinas et al (2021)). This becomes particularly germane when a significant risk of non-routine maintenance exists. 
This paper aims to provide new, up-to-date cost functions (i.e. cost vs. flow) for low-pressure membrane technologies, and to use these to assess potential cost benefit. The functions relate to total cost expressed as the present value (PV), i.e. the cost projected to the present day, and encompass all key cost contributors (Table 3) along with the impact of process upsets and subsequent non-scheduled maintenance on OPEX. Such interventions inevitably incur a higher cost than routine maintenance, since they often arise outside normal working hours, may be conducted by external contractors, and can involve extended time periods. All key data, both CAPEX and OPEX, is taken largely from the plant owner-operators, i.e. the water utilities, from across the UK.

\section{$2 \quad$ Methodology}

The calculation of PV proceeded through capturing the baseline data (Table 3) and then:

1. determining OPEX, or $L_{O}$, in units of $£ / \mathrm{m}^{3}$ permeate from standard expressions (Appendix B-D), the principal contributors being energy and chemical reagent consumption $\left(L_{E}\right.$ and $L_{R}$ respectively), membrane replacement $\left(L_{M}\right)$, and waste disposal $\left(L_{W}\right)$ which do not change with flow capacity $(Q)$;

2. determining labour effort (FTE, or full-time equivalent) and thus cost $\left(L_{L}\right)$ as a function of $Q$;

3. determining CAPEX, $L_{C}$, as a function of $Q$;

4. normalising all parameters against $Q$ to generate specific cost $\left(L^{\prime}\right)$ in units of $£ \mathrm{k}$ per $1000 \mathrm{~m}^{3} / \mathrm{d}$ (or $£$ per $\mathrm{m}^{3} / \mathrm{d}$ ) flow capacity;

5. determining the total OPEX contribution to PV through discounting, assuming an annual discount factor value and a 20-year life cycle time; and

summing the normalised OPEX and CAPEX cost contributors $\left(L^{\prime} O\right.$ and $L^{\prime}{ }_{C}$ respectively) to produce PV', the total cost per unit flow capacity over the plant life cycle 
Table 3. Data sources and ranges of values for routine operation

\begin{tabular}{|c|c|c|c|}
\hline Cost component & Source & Value/range & Comment and/or number of data \\
\hline \multicolumn{4}{|l|}{ CAPEX-related } \\
\hline Membrane module cost & Owners, web & $\begin{array}{l}£ 19-60 \mathrm{~m}^{-2} \\
\text { membrane area; } \\
£ 0.0024-0.011 \mathrm{~m}^{-3}\end{array}$ & $\begin{array}{l}\text { Dependent on supplier, model and contract. Average price taken for specific product, zero price } \\
\text { inflation assumed; } 9 \text { products }\end{array}$ \\
\hline Membrane module surface area & Owners, web & $21-50 \mathrm{~m}^{2}$ & Product/technology dependent; 9 products \\
\hline $\begin{array}{l}\text { Normalised membrane } \\
\text { technology component cost, } L_{C}^{\prime} \\
\text { OPEX-related }\end{array}$ & Owners & $\begin{array}{l}£ 0.035-0.081 \text { per } \\
\mathrm{m}^{3} / \mathrm{d} \text { flow }\end{array}$ & $\begin{array}{l}\text { Calculated from CAPEX data either provided directly or estimated as a proportion of the total } \\
\text { CAPEX; } 15 \text { data. }\end{array}$ \\
\hline Conversion & Literature & $95 \%$ & Nominal value \\
\hline Electrical energy cost & Owners & $\begin{array}{l}£ 0.125 \mathrm{kWh}^{-1} \\
2020 \text { price }\end{array}$ & Mean, cross-sector value assumed \\
\hline $\begin{array}{l}\text { Energy cost index (future energy } \\
\text { cost projections) }\end{array}$ & UK Govt. & $0 \%$ net & $\begin{array}{l}\text { Based on a predicted change of between }-0.7 \% \text { and }+0.8 \% \text { in energy costs per annum between } 2020 \\
\text { and } 2040 \text { (DBEIS, 2019) }\end{array}$ \\
\hline $\begin{array}{l}\text { Energy consumption, liquid } \\
\text { pumping }\end{array}$ & Calculated & $0.12-0.18 \mathrm{kWh} / \mathrm{m}^{3}$ & Determined from feedwater pressure recorded from site, assuming a pumping efficiency of $70 \%$ \\
\hline Valve \& actuator replacement & Owners & $£ 1200$ & Blanket value assumed \\
\hline Labour cost & Owners & $\begin{array}{l}£ 35 \mathrm{~h}^{-1} \text { normal; } £ 65 \\
\mathrm{~h}^{-1} \text { overtime }\end{array}$ & $\begin{array}{l}\text { Mean, cross-sector values assumed throughout for normal and overtime rates, inclusive of } \\
\text { overhead. }\end{array}$ \\
\hline Labour effort & Calculated & $1700 \mathrm{~h} / \mathrm{y}$ & i.e. 1 FTE-y $=£ 59,500$ \\
\hline Waste disposal cost & Web & $£ 0.003 \mathrm{~m}^{-3}$ & Sewer discharge disposal assumed at mean, cross-sector value \\
\hline CIP volume & Suppliers & $\begin{array}{l}0.0007-0.013 \mathrm{~m}^{3} \\
\text { reagent } / 1000 \mathrm{~m}^{3}\end{array}$ & Dependent on CIP frequency \\
\hline CIP frequency & Owners & per $3.5-30 \mathrm{~d}$ & Determined by clogging events \\
\hline
\end{tabular}


The influence of process upset events on the PV can then be appraised, along with the magnitude of the process upset cost relative to the CAPEX.

\subsection{CAPEX, LC}

A plant life of 20 years was assumed. The CAPEX $L_{C}$ was determined for the membrane technology component of the installation, including the mechanical and electrical (M\&E) costs pertaining to the membrane technology but excluding all civil engineering costs. In cases where only the CAPEX of the complete installation was provided, the membrane technology component cost was estimated based on knowledge of the construction provided by the owneroperators.

All CAPEX was converted to 2020 GBP (Great British Pounds) using year-on-year UK consumer price index (CPI) values, for which historical information (App A) indicates a roughly linear trend with year $(y)$ since the turn of the millennium:

$$
\mathrm{CPI}=2.002 y-3933
$$

Applying this to $75 \%$ of the investment cost, i.e. excluding the membrane component, the present-day (year 2020) CAPEX becomes:

$$
L_{C}=83 L_{C, y} /(111-2(2020-y))+0.25 L_{C, y}
$$

Equation 4 assumes the membrane module component costs to (a) make up $25 \%$ of the investment cost, and (b) be subject to zero inflation: a review of the membrane prices, as 
provided by the owner-operators, from 2005 onwards suggested the price to be very erratic with no defined increasing or decreasing trend.

\subsection{OPEX, Lo}

\subsubsection{Electrical energy}

The cost incurred by the total electricity consumption on site represents the most significant OPEX contribution. However, to maintain consistency, the electrical cost associated only with the operation of the membrane plant itself needs to be determined in isolation.

Contributions to the specific electrical energy consumption $L_{E}$ in $\mathrm{kWh} / \mathrm{m}^{3}$ permeate for membrane operation relate to:

a) liquid pumping during filtration and backflushing,

b) compressed air used for operation of the pneumatic valves, for conducting the pressure decay test (PDT), and for the backwash cycle, and

c) heating of chemical reagents used for the clean in place (CIP).

The liquid pumping energy consumption during backflushing can be assumed to be comparable to that during filtration, such that the overall $L_{E}$ relates to the inverse conversion (i.e. the ratio of permeate to feed flow). Accordingly, the liquid pumping energy is in the region of $\mathbf{0 . 1 4 6}$ $\mathbf{k W h} / \mathbf{m}^{\mathbf{3}}$ (App B). In comparison, the energy associated with delivering compressed air for the backflush is negligible, according to a similar first-principles calculation (App B).

Calculation of the energy associated with heating of the chemical cleaning reagents (App C) suggest that this component contributes $0.0010 \mathbf{~ k W h} / \mathbf{m}^{3}$ for a typical $30 \mathrm{~d}$ CIP interval. This contribution increases with decreasing CIP interval. 


\subsubsection{Chemicals consumption}

The chemical reagents used for the CIP comprise sodium hypochlorite $(\mathrm{NaOCl})$ or caustic soda $(\mathrm{NaOH})$, used for control of organic foulants, combined with sulphuric acid $\left(\mathrm{H}_{2} \mathrm{SO}_{4}\right)$ and/or citric acid (CA) for metal oxides removal. Based on prices for bulk reagent supply and typical doses used for cleaning, the cost incurred is $\mathbf{2 0 . 0 0 0 2 2}$ per $\mathbf{~ m}^{\mathbf{3}}$ for routine operation (i.e. a $30 \mathrm{~d}$ CIP interval) (App C).

\subsubsection{Critical component replacement}

The component incurring the highest cost on replacement is the membrane module itself. According to the available data (App D) the membranes costed between $£ 19$ and $£ 60$ per $\mathrm{m}^{2}$ depending on the make and model. The membranes incurring the highest cost were the capillary tube (CT) membranes which operate with in-to-out flow during the filtration cycle. This flow regime provides higher fluxes than the out-to-in hollow fibre (HF) configuration, such that the range of costs per $\mathrm{m}^{3}$ permeate are broadly comparable.

Replacement costs are sensitive to both the membrane cost per unit permeate flow, given by the membrane price:flux ratio in $£ / \mathrm{m}^{2}$ per $\mathrm{L} /\left(\mathrm{m}^{2} . \mathrm{h}\right)$ or $\mathrm{LMH}$, and the membrane life. Whilst a design membrane life value of 7 years has been used as the baseline in the costings, practical experience suggests that values are generally lower than this - and dramatically so when severe process upsets have taken place.

The analysis focused on two different HF modules (HF1 and HF2) and a CT module (CT), all from established global suppliers. 


\subsection{Present value, $P V$}

The PV is a function of the CAPEX $\left(L_{C}\right)$ and $\operatorname{OPEX}\left(L_{O}\right)$ cost contributions (Jalab et al, 2019):

$$
\mathrm{PV}=\sum_{t=0}^{t=n} \frac{L_{C_{t=0}}+L_{O_{t}}}{(1+\mathbf{D})^{t}}
$$

D being the discount factor and $n$ the total plant life (or amortisation period), taken as 20 years in the current analysis. A D value of $3.5 \%$ was used throughout, as currently used by the UK Department of Transport for civil engineering project cost projections for periods of up to 30 years (UKDfT, 2021). The baseline date of 2021 was used, such that the calculated $P V$ refers to the total projected cost from 2021 to 2041.

Annualising all scheduled OPEX, including membrane replacement, simplifies this equation:

$$
\mathrm{PV}=Q L_{C}+365 Q L_{O} \sum_{t=0}^{t=n} \frac{1}{(1+\mathbf{D})^{t}}=Q\left(L_{C}+k L_{O}\right)
$$

where $Q$ is the permeate flow $\left(Q_{\text {feed }} / \theta, \theta\right.$ being the conversion) and $k$ a constant depending on the units employed. All cost parameters can be normalised against the flow (i.e. $L / Q$ ) to give the specific cost L' or PV' in $£ \mathrm{k}$ per $\mathrm{m}^{3} / \mathrm{d}$ flow.

A cost of $£ 0.125$ per $\mathrm{kWh}$ was assigned to a unit of electricity at the baseline year of 2020 (Table 2). The trend in future electrical UK energy costs presented in the most recent UK government report (DBEIS, 2019) stipulates a predicted change of between $-0.7 \%$ and $+0.8 \%$ in energy costs per annum between 2020 and 2040. The current cost was therefore assumed to be unchanged over the project life cycle (i.e. zero energy cost inflation). 


\section{$3 \quad$ Results and discussion}

\subsection{Capital expenditure (CAPEX), $L_{C}$}

Extracted CAPEX data for 15 reference installations (Fig. 1) suggests that $L_{C}: Q$ is best represented by a polynomial trend, $Q$ being the design flow capacity, within the range 4,000 $160,000 \mathrm{~m}^{3} / \mathrm{d}:$

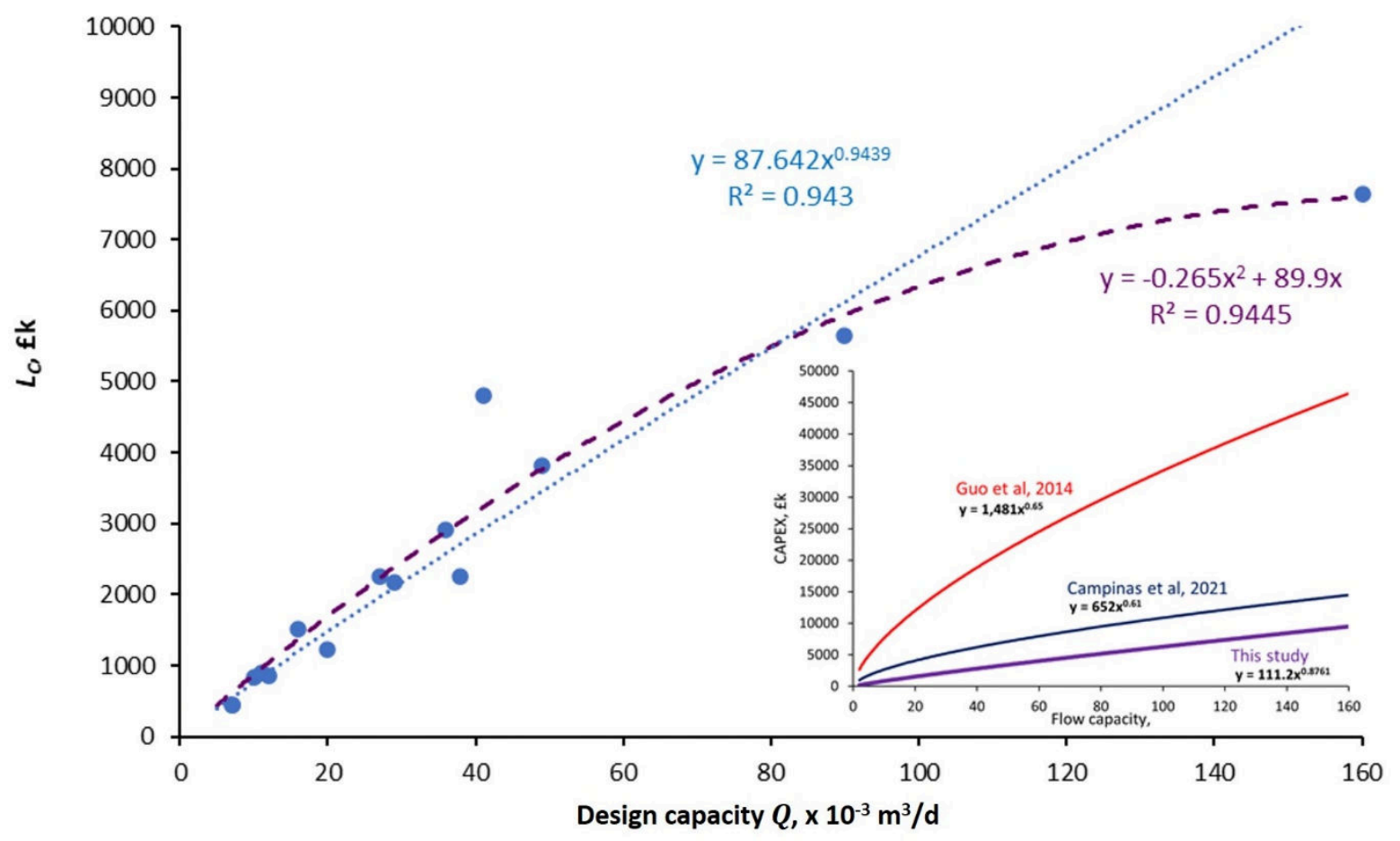

Figure 1: Trend in CAPEX (LC) with design flow capacity $Q, 14$ reference installations. Inset: comparison with published CAPEX curves, Equations $1 \& 2$ (Guo et al, 2014; Campinas et al, 2021). All costs converted to 2020 GBP.

$$
L_{C}, £ \mathrm{k}=90 Q-0.265 Q^{2}
$$

The above equation indicates the specific CAPEX $L^{\prime} C$, in $£ \mathrm{k}$ per $1000 \mathrm{~m}^{3} / \mathrm{d}$ flow capacity, to be given by: 


$$
L^{\prime}{ }_{C} £ \mathrm{k}=90-0.265 Q
$$

This equation was used in all subsequent PV' calculations.

Expressing the trend as a power function, in keeping with most published trends (Fig. 1, inset), reveals the values to be substantially lower than that presented by Campinas et al (2021) and, in particular, by Guo et al (2014). This may be because the CAPEX determined in the current study (a) relates only to the membrane technology component, and explicitly excludes civil engineering costs, (b) refers to the design capacity of the installation, and (c) refers specifically to the UK region, as distinct from the US or mainland Europe. The other notable difference is in the exponent value, which indicates there to be a much lower economy of scale than that suggested in the two previous reports.

\subsection{Operating expenditure (OPEX), Lo}

\subsubsection{Flow-independent parameters}

Values for all flow-independent OPEX-related parameters (Table 4) were taken or estimated from site information, extracted from literature publications and/or calculated from standard expressions (App 2-4). Accordingly, all contributions to $L_{O}$, the cost per unit treated volume (and, by implication, $L^{\prime} O$, the cost per unit flow rate) other than the labour effort $L_{L}$ are considered independent of plant flow capacity. Summing all components:

$$
L_{O, Q} \text { independent }=L_{E}+L_{M}+L_{R}+L_{W}=\mathbf{E 0 . 0 2 8 8} / \mathbf{m}^{\mathbf{3}}
$$

The distribution of these costs indicates the expected dominance of energy consumption (Fig. 2). Waste disposal costs are notional, since they are highly site specific. 
Table 4. Assumed data values, OPEX contributors

\begin{tabular}{l|rll}
\hline Parameter & Value & Units & Ref \\
\hline Energy consumption & & & \\
Energy consumption & 0.147 & $\mathrm{kWh} / \mathrm{m}^{3}$ & \\
Energy cost & 0.125 & $£ / \mathrm{kWh}$ & \\
Energy cost, $\boldsymbol{L}_{\boldsymbol{E}}$ & $\mathbf{0 . 0 1 7 3}$ & $£ / \mathrm{m}^{3}$ & App B \\
Membrane replacement & & & \\
Membrane element cost & 25 & $£ / \mathrm{m}^{2}$ & \\
Life & 7 & $\mathrm{y}$ & \\
Net flux & 45 & $\mathrm{LMH}$ & \\
Membrane replacement cost, $\boldsymbol{L}_{\boldsymbol{M}}$ & $\mathbf{0 . 0 0 9 1}$ & $£ / \mathrm{m}^{3}$ & App D \\
Chemical reagent consumption & & & \\
Chemicals cost, $\boldsymbol{L}_{\boldsymbol{R}}$ & $\mathbf{0 . 0 0 0 2}$ & $£ / \mathrm{m}^{3}$ & App C \\
Waste disposal & & & \\
Waste generation rate & - & $\mathrm{kg} / \mathrm{d}$ & \\
Waste disposal cost, $\boldsymbol{L}_{W}$ & $\mathbf{0 . 0 0 1 1}$ & $£ / \mathrm{m}^{3}$ & - \\
TOTAL & & & \\
\hline
\end{tabular}

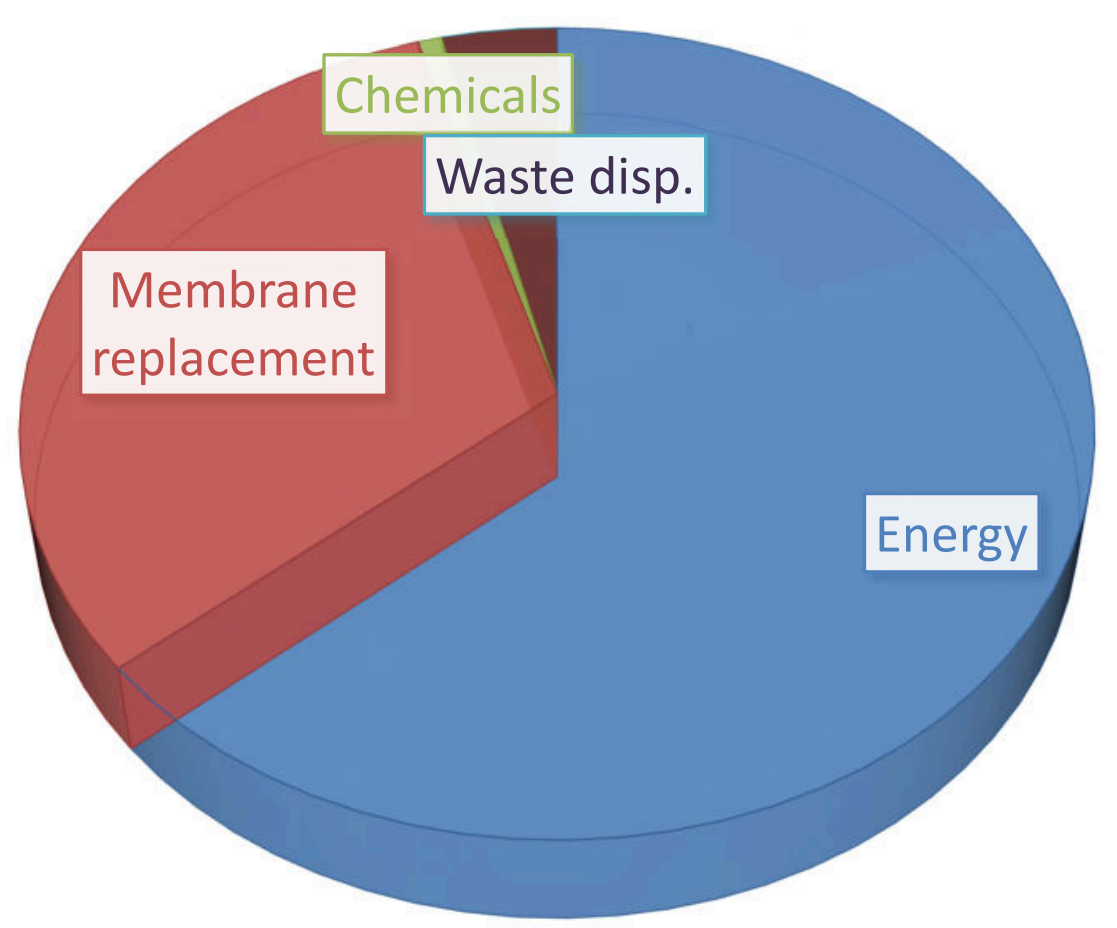

Figure 2: Distribution of non-flow capacity related OPEX contributors (from Table 4). 


\subsubsection{Labour}

12 data sets were used to determine the labour cost as a function of design flow capacity (Fig.

3). Data were either extracted directly as costs, or determined from allocated hours or full-time equivalents (FTE) based on the mean hourly gross rate of $£ 35$ (Table 3). Labour costs included both sub-contracted and water company staff effort. In most cases these were itemised separately by the owner operators.

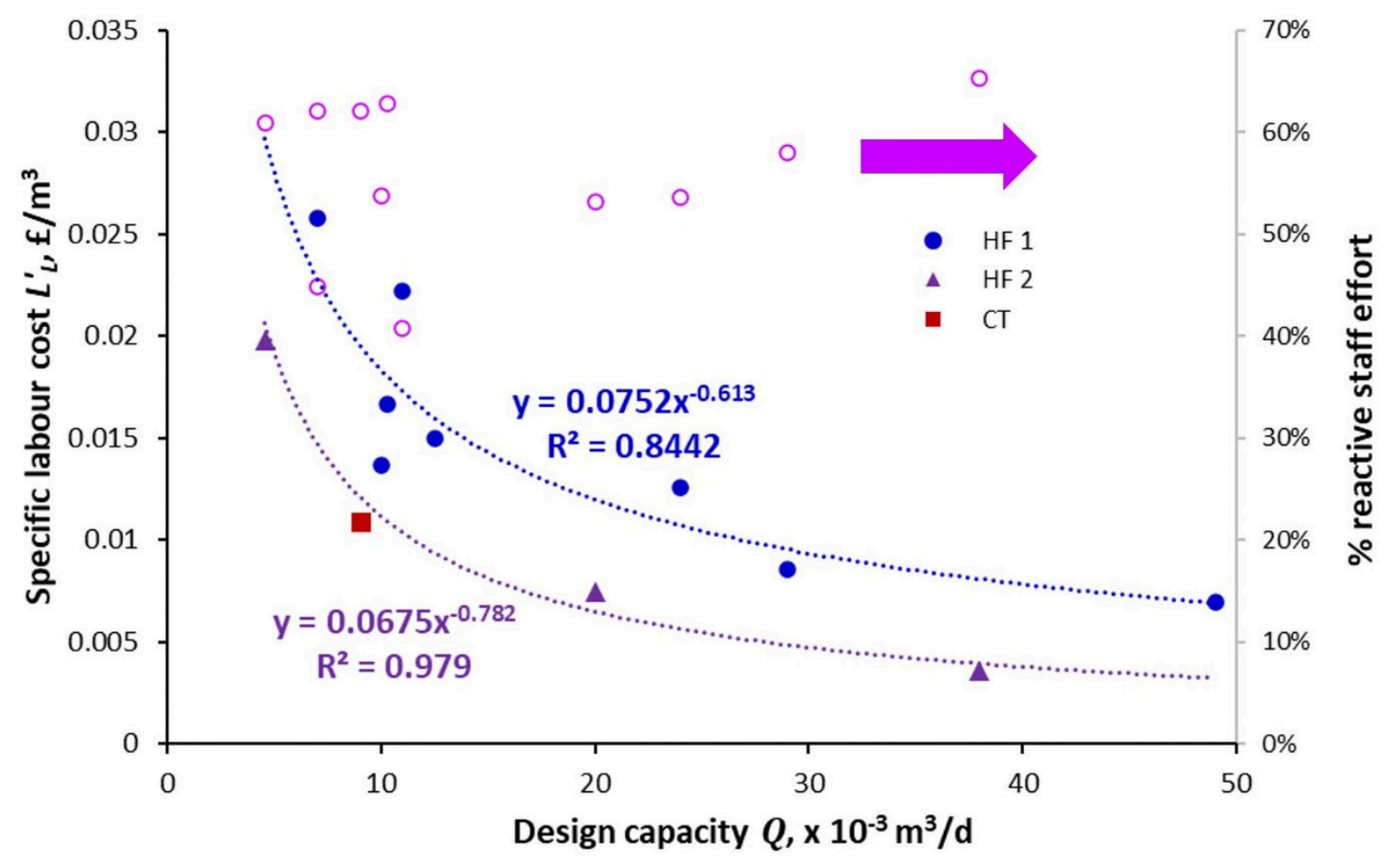

Figure 3: Specific labour cost in $£ / \mathrm{m}^{3}$ permeate vs design flow capacity

A distinction was made between the eight data points relating to the most widely used HF technology (HF1), and the other technologies (HF2 and CT, App D). Also, for all but one of the data points, "planned" and "reactive" staff effort were differentiated. No trend with flow capacity was evident for the percentage reactive effort with flow, the average being $56 \pm 8 \%$ (standard deviation) across the entire flow range of 4,000-50,000 $\mathrm{m}^{3} / \mathrm{d}$ (Fig. 3). 
The specific labour cost (planned + reactive) was found to decrease with flow according to the following power-law expressions for the different membrane technologies:

$$
\begin{array}{lll}
L^{\prime}{ }_{L}=0.0752 Q^{-0.613} & H F 1 & \mathrm{R}^{2}=0.8442 \\
L^{\prime}{ }_{L}=0.0675 Q^{-0.782} & H F 2, C T & \mathrm{R}^{2}=0.979
\end{array}
$$

Equation 10 was used for all subsequent PV correlations, since eight of the 15 sites for which CAPEX data were available were based on the HF1 technology. The exponent value of -0.613 is in good agreement with the value of -0.59 used by Campinas et al (2021), taken from Mulder et al (2015).

\subsection{Specific present value, $P V^{\prime}$}

Equation 7 was used to compute specific present values (PV' in $\mathrm{kf}$ per $1000 \mathrm{~m}^{3} / \mathrm{d}$ flow capacity), along with the capital and operating expenditure contributions, as a function of $Q$

(Fig. 4). The trends encompass the expression for the flow-related labour cost (Equation 10), also shown in isolation, and the single mean value for the flow-independent parameters (Equation 9). Trends relate to a discount factor of 3.5\% and a life cycle of 20 years.

According to all assumptions made, the overall total PV' is given by the sum of the three individual components of specific $\operatorname{CAPEX}\left(L^{\prime} C\right)$, and the flow-independent and flow-dependent contributions to the specific OPEX $P V$ :

$$
\mathrm{PV}^{\prime}=-0.652 Q^{2}-90 Q+456 Q^{-0.613}+174
$$


The constant value of 174 represents the contribution of the flow-independent parameters, depicted as the horizontal dotted line in Figure 4, and is most sensitive to the energy consumption and membrane life (Table 4). All other terms include the flow capacity $Q$ and are sensitive to all assumptions made in interpreting the data set.

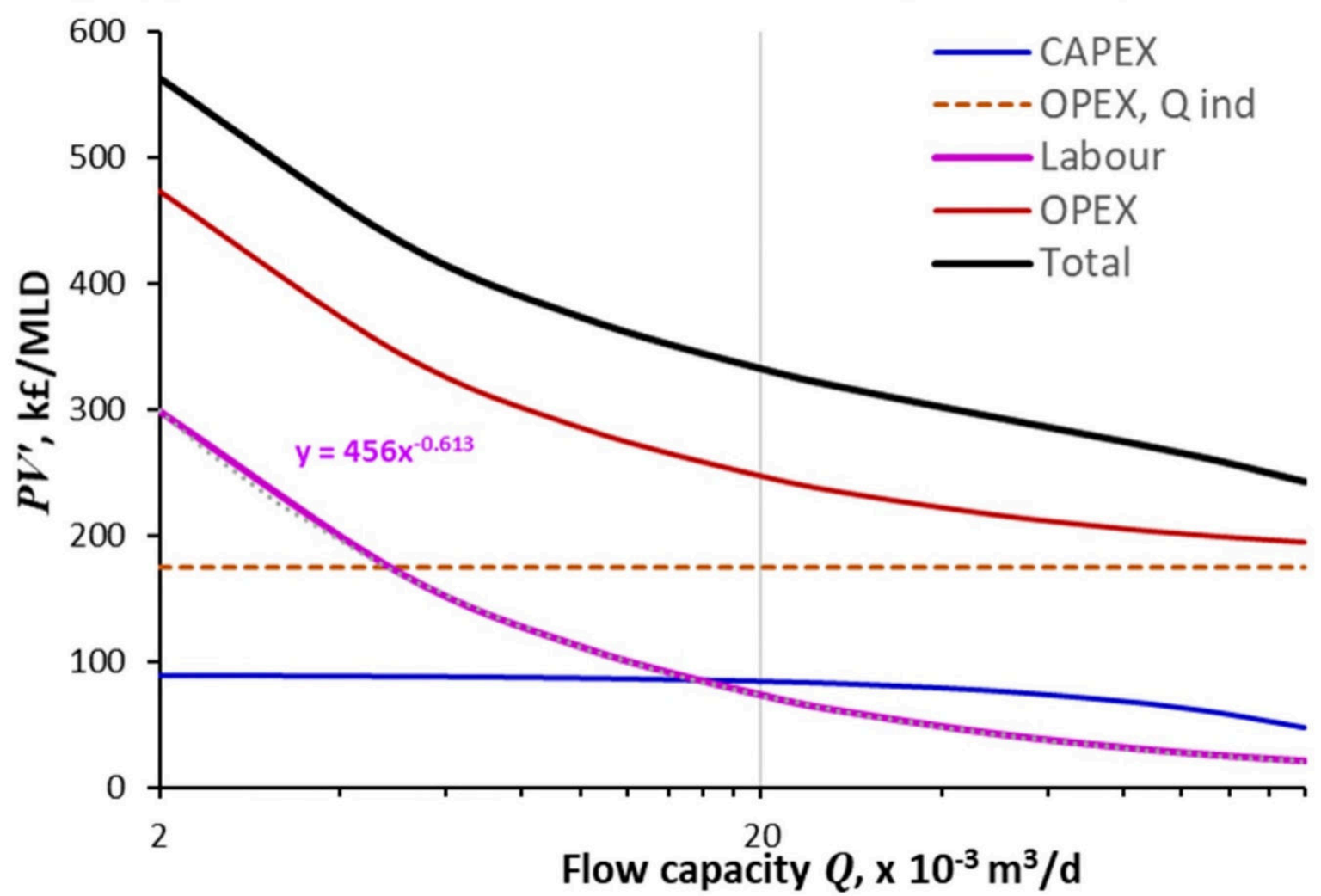

Figure 4: $\quad$ Specific present value (PV' in $£$ per $\mathrm{m}^{3} / \mathrm{d}$ flow capacity) vs plant flow capacity for CAPEX, flowindependent OPEX, Labour OPEX, total OPEX and total cost.

According to Figure 4:

1. The operating PV' decreases more sharply with flow than the capital $P V$;

2. The total operating PV' is 3-6 times the capital PV over all flow capacities;

3. The labour cost makes up more than half of the operating cost at flow capacities below $5,000 \mathrm{~m}^{3} / \mathrm{d}$, increasing sharply with decreasing flows;

4. The labour PV' exceeds the capital PV' at flows below $15,000 \mathrm{~m}^{3} / \mathrm{d}$; 
The above outcomes are consistent both with expectations and cost analyses reported elsewhere for low-pressure membrane installations both for potable water (Campinas et al, 2021; Guo et al, 2014) and wastewater (Jalab et al, 2019). Whilst the absolute values of the labour costs are much lower than those determined for wastewater membrane plants (Qiblawey and Judd, 2019; Young et al, 2013), they none-the-less contribute more significantly to the total OPEX due largely to the relatively low energy demand of potable water membrane filtration compared with membrane bioreactors used for wastewater treatment. At flow capacities below $6,000 \mathrm{~m}^{3} / \mathrm{d}$ labour costs exceed the electrical energy cost, becoming the primary contributor to OPEX.

Figure 4 correlates cost with design flow capacity. Very few membrane plants operate at or even near their design capacity for any extended period. A conservative assumption would be that the actual flow is, on average, $75-80 \%$ of the full flow. This would then commensurately increase the flow-normalised labour and capital costs, but leave all other normalised OPEX contributions largely unchanged. For such an assumption the labour cost would make up more than half the operating cost at flows below 27,000-32,000 $\mathrm{m}^{3} / \mathrm{d}$. This implies that, for most of the plants surveyed, the labour cost represents the largest component of the OPEX. Moreover, the CAPEX cost curve becomes more closely aligned with that of Campinas et al, 2021.

\subsection{Impacts of process upsets}

Causes of process upsets can generally be identified as:

1. hardware replacement;

2. excessive membrane integrity failure; and

3. ineffective chemical cleaning. 
Hardware most prone to failure is normally the actuators and valves, to which a nominal replacement cost of $£ 1500$ including labour can be assigned. This would imply that valve replacement costs exceed $£ 0.001$ per $\mathrm{m}^{3}$ if more than 1 valve per $1,000 \mathrm{~m}^{3} / \mathrm{d}$ flow is replaced every four years.

Membrane integrity is monitored through the off-line pressure decay test (PDT). A PDT failure necessitates identifying the module responsible for the failure followed by repair. Whilst identification and repair protocols have been improved since the initial implementation of membrane technology in the UK in the early 2000s, it remains a manual and often labourintensive process.

Ineffective chemical cleaning, i.e. a poor and short-term recovery or permeability following a CIP, is normally indicative of clogging of the HF membrane channels, which is not substantially removed by chemical cleaning. Its impacts can be very onerous with reference to many cost components (Table 5). There was no evidence of similar events for CT configuration.

Table 5. Process upset impact on six $\operatorname{OPEX}\left(L_{O}\right)$ components

\begin{tabular}{|c|c|c|c|}
\hline Cost contributor & Clogging issues & Integrity issues & Impacts \\
\hline Spec. energy cost, $L^{\prime}{ }_{E}$ & Increases slightly & Unchanged & $\begin{array}{l}\text { Increased heating requirement } \\
\text { and CIP reagent demand }\end{array}$ \\
\hline Spec. membrane replacem. cost, $L^{\prime}{ }_{M}$ & Increases & Increases & Decreased membrane life \\
\hline Spec. chemicals cost, $L_{C}$ & Increases & Unchanged & Increased CIP frequency \\
\hline Spec. labour cost, $L_{L}^{\prime}$ & Increases & Increases & $\begin{array}{l}\text { Increased effort, } \\
\text { removing/replacing modules }\end{array}$ \\
\hline Spec. waste disp. cost, $L^{\prime}{ }_{W}$ & Increases slightly & Unchanged & Increase in waste chemicals \\
\hline
\end{tabular}

The impact of operating under challenged conditions can be assessed based on the following approaches:

a) comparison of labour costs associated with planned and reactive staff effort; and

b) ad hoc site-based information. 
The increase in operating costs attributable to the process upset can then be compared to the capital cost, to assess whether it is realistic to increase the level of investment (quantified as the specific CAPEX $L^{\prime} C$ ) to reduce the risk of process upset.

\subsubsection{Planned vs. reactive staff effort}

According to the current analysis, the reactive staff effort makes up $56 \pm 8 \%$ of the total staff effort. If it is assumed that the reactive effort can be obviated by appropriate process design modifications, then this assigns the maximum supplementary CAPEX $\Delta L^{\prime}{ }_{C}$ value.

According to this assumption, and based on the data depicted in Figure 5, eliminating the cost associated with reactive labour $\left(\Delta L^{\prime}{ }_{L} \sim 50 \%\right.$ of $\left.L^{\prime}{ }_{L}\right)$ produces a PV cost saving of between $20 \%$ (at $160,000 \mathrm{~m}^{3} / \mathrm{d}$ design flow capacity) and $180 \%$ (at $2,000 \mathrm{~m}^{3} / \mathrm{d}$ flow capacity) of the CAPEX. In absolute terms this equates to $£ 370 \mathrm{k}$ at the lowest flow and $£ 2.0 \mathrm{~m}$ at the highest.

The $L^{\prime} L: L{ }^{\prime} O$ appears to be largely insensitive to the base values assumed for the key parameter of design flux. For example, a 30\% change in the design flux (from $45 \mathrm{LMH}$ to either $30 \mathrm{LMH}$ or $60 \mathrm{LMH}$ ), producing a corresponding $8 \%$ change in the CAPEX, produces no more than a $3 \%$ change in the absolute $L^{\prime}{ }_{L}: L^{\prime} O$ percentage value.

\subsubsection{Impact of excessive pinning}

Anecdotal evidence from the owners, including published commercial data (Bristol Water, 2018), suggests that supplementary effort of 0.4 FTE associated pinning is perceived as being unacceptably high for a $25,000-30,000 \mathrm{~m}^{3} / \mathrm{d}$ flow capacity plant. Using the same approach as previously this flow equates to a labour PV of £680k over a 20 -year cycle, compared to a CAPEX PV of $\sim £ 2.3 \mathrm{~m}$. So, in this instance an investment of up to $\sim 30 \%$ of the CAPEX for this 
plant capacity would be cost effective if this resulted in a 0.4 FTE reduction in the labour effort from the reduced pinning frequency. It would also significantly reduce the risk of compliance failure, as well increasing the membrane life.

\subsubsection{Impact of clogging}

As indicated in Table 5, clogging impacts negatively on all key OPEX contributors due to increase incurred in both the labour effort and the CIP frequency. The latter increases both the chemicals and energy consumption, since the CIP requires heating of the reagents (App C).

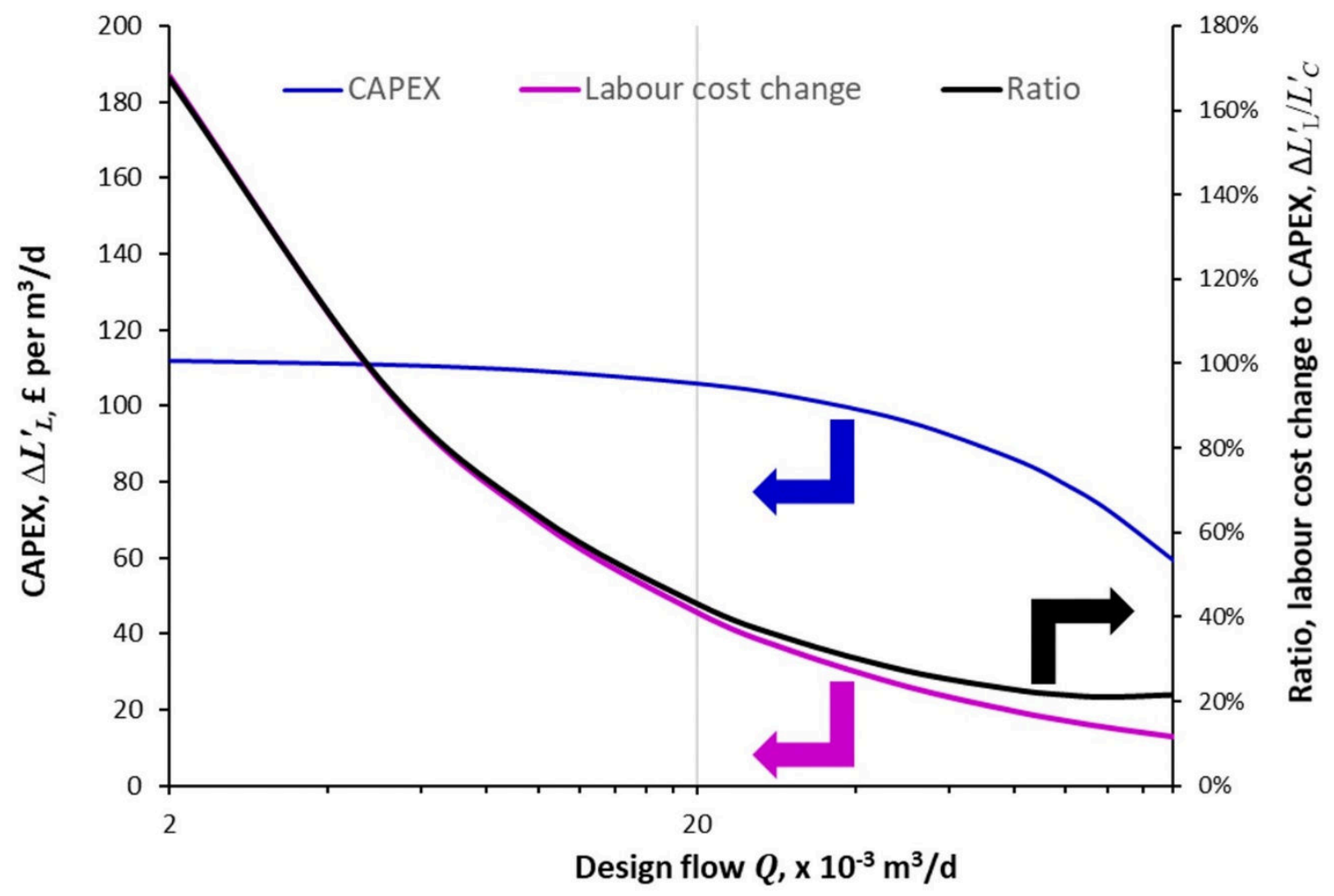

Figure 5: Impact of eliminating reactive staff effort component of labour cost, as a proportion of capital cost

Under extreme conditions the CIP frequency may be reduced from every $30 \mathrm{~d}$ to every $3.5 \mathrm{~d}$. In this case, the energy demand would increase by $5 \%$ from 0.147 to $0.155 \mathrm{kWh} / \mathrm{m}^{3}$, with a corresponding increase in the specific energy cost, $L_{E}$, to $£ 0.0194$ per $\mathrm{m}^{3}$. 
The chemicals cost increases proportionately: a decrease from 30 to 3.5 days increases the chemical usage by a factor of $30 / 3.5$, i.e 8.6. This cost therefore increases to $£ 0.002$ per $\mathrm{m}^{3}$. The waste generation would also increase, although the primary waste stream is the backwash water rather than the spent CIP reagents.

The membrane life is also affected by clogging. A conservative estimate would be a reduction to 3 years from the baseline life 7 years. The specific membrane replacement cost $L_{M}$ increases commensurately, from $£ 0.0091$ to $£ 0.0211$ per $\mathrm{m}^{3}$.

However, the most significant OPEX impact is on the labour cost. According to experience, an increase in labour effort by between 26 and $40 \%$ can arise during the clogging event for a 10$50,000 \mathrm{~m}^{3} / \mathrm{d}$ plant according to information provided from two of the sites studied. Taking an average of these two ranges, a $33 \%$ increase in labour effort for a 30,000 $\mathrm{m}^{3} / \mathrm{d}$ plant increases the specific labour cost from $£ 0.0094$ to $£ 0.0125$ per $\mathrm{m}^{3}$.

The overall impact of clogging is thus to increase the OPEX $L_{O}$ from $£ 0.0382$ to $£ 0.0568$ per $\mathrm{m}^{3}$, a change of 0.0186 per $\mathrm{m}^{3}$ or $£ 560$ a day for a $30,000 \mathrm{~m}^{3} / \mathrm{d}$ capacity installation. Thus, a 3month clogging event incurs a cost of $\sim £ 50 \mathrm{k}$ in addition to the routine running costs, representing a $\sim 50 \%$ increase.

\section{Conclusions}

A cost analysis of low-pressure membrane filtration for potable water production from inland raw waters has been conducted based largely on data provided by the installation 
owner/operators and their service providers. Outcomes indicate the capital expenditure (CAPEX) to be significantly lower than that suggested by previously published trends, and for the economy of scale (the exponent value in the power law trend) to be less. The total operational expenditure evaluated as the present value (i.e. the OPEX PV) was found to exceed the CAPEX by a factor of 3-6 over the 20-year life cycle, the difference increasing with decreasing flow capacities.

Labour costs, segregated into routine (or "planned") and non-routine ("reactive") trends and normalised against flow rate, were found to increase with decreasing flow capacity, exceeding the contribution of energy to cost at flows below $5,000 \mathrm{~m}^{3} / \mathrm{d}$ and exceeding the CAPEX at flows below $30,000 \mathrm{~m}^{3} / \mathrm{d}$. "Reactive" labour contributed around $50 \%$ of the total labour cost, and was associated with excessive membrane pinning (i.e. repair of breached membranes) and/or permeability recovery following clogging events.

Since the cost incurred by process upsets increases as a proportion of the total cost with decreasing flow capacity, the cost effectiveness of any remedial measures depends on (a) the total period of the process upset in which the additional cost is incurred, and (b) the absolute cost of the remedial measure, as a function of flow capacity. This then provides a benchmark for determining the potential cost benefit from modifying the installation to reduce the risk of process upsets. 


\section{Acknowledgements}

This work was made possible through the UK Higher Education Innovation Fund. The authors gratefully acknowledge the cooperation of the various UK water utilities in providing the data required for the analysis, and for the accompanying technical advice and information.

\section{References}

Arhin, S. G., Banadda, N., Komakech, A. J., Pronk, W., Marks, S. J., 2019. Application of hybrid coagulationultrafiltration for decentralized drinking water treatment: Impact on flux, water quality and costs. Water Sci. Technol: Water Supply 19(7), 2163-2171.

Bai, H., Lin, Y., Qu, H., Zhang, J., Zheng, X., Tang, Y., 2020. Technical and economic evaluation of wwtp renovation based on applying ultrafiltration membrane. Membranes 10(8), 1-16.

Bristol Water, 2018. C5B Technical Annex 15 Treatment Works Strategic Maintenance Investment Case: Technical Approach and Business Case, NTPBP-INV-STR-0542.

Buzatu, P., Qiblawey, H., Odai, A., Jamaleddin, J., Nasser, M., Judd, S. J., 2018. Clogging vs. fouling in immersed membrane bioreactors. Water Res. 144, 46-54.

Campinas, M., Viegas, R. M. C., Silva, C., Lucas, H., Rosa, M. J. 2021. Operational performance and cost analysis of PAC/ceramic MF for drinking water production: Exploring treatment capacity as a new indicator for performance assessment and optimization. Sep. Purif. Technol. 255, 117443

DBEIS, 2019. Department for Business, Energy \& Industrial Strategy report: Updated energy and emissions projections, Annex M: Growth assumptions and prices. https://www.gov.uk/government/publications/updatedenergy-and-emissions-projections-2019, accessed 20/12/2020.

Ferrer, O., Casas, S., Galvañ, C., Lucena, F., Bosch, A., Galofré, B., Mesa, J., Jofre, J., Bernat, X., 2015. Direct ultrafiltration performance and membrane integrity monitoring by microbiological analysis. Water Res., 83, 121131. 
Guerra K., Pellegrino J., 2012. Investigation of low-pressure membrane performance, cleaning, and economics using a techno-economic modelling approach. Science and Technology Program Report No. 174., U.S. Department of the Interior, Bureau of Reclamation (USA).

Guerra, K., Pellegrino, J., 2013. Development of a techno-economic model to compare ceramic and polymeric membranes. Sep. Sci. Technol. (Philadelphia) 48(1), 51-65.

Gumerman, R.C., Culp, R.L., Hansen, S.P., Lineck, T.L., 1979. Estimating Water Treatment Costs: Cost curves applicable to 2,500 gpd to $1 \mathrm{mgd}$ treatment plants. Environmental Protection Agency, Office of Research and Development, Municipal Environmental Research Laboratory.

Guo, T., Englehardt, J., Wu, T., 2014. Review of cost versus scale: water and wastewater treatment and reuse processes. Water Sci. Technol. 69(2), 223-234.

Hurwitz, G., Bhattacharjee, S., Seo, E., Wang, J., Severt, A., Temple, J., Nguyen, J., Koehler, J., Hoek, E.M.V., 2018. Field testing of PolyCera ${ }^{\circledR}$, PES, and PVDF ultrafiltration membranes in municipal tertiary filtration: Impacts of membrane polymer chemistron fouling, cleaning, energy, and cost. Desalin. Water Treat. 111, 39-47. Jalab, R., Awad, A., Nasser, M., Miner-Matar, J., Adham, S., Judd, S., 2019. An empirical determination of the whole-life cost of FO-based open-loop wastewater reclamation technologies. Water Res. 163, 114879.

Judd, S.J., 2017. Membrane technology costs, and me, Water Res. 122, 1-9.

Lee, J., Son, K. P., Park, P., \& Noh, S. H., 2020. Performance and cost comparison of a gravity-driven free-end membrane and other water filtration systems for household water treatment. Water Sci. Technol.: Water Supply $20(3), 837-850$.

Lee, S., Yamashita, N., Tanaka, H., 2019. How fiber breakage reduces microorganism removal in ultrafiltration for wastewater reclamation. Food Environ. Virol., 11(2), 167-177.

Mulder, M., Antakyali, D., Ante, S., 2015. Costs of Removal of Micropollutants from Effluents of Municipal Wastewater Treatment Plants - General Cost Estimates for the Netherlands based on Implemented Full Scale Post Treatments of Effluents of Wastewater Treatment Plants in Germany and Switzerland. STOWA and Waterboard the Dommel, The Netherlands.

Qiblawey, H., Judd, S.J., 2019. Industrial effluent treatment with immersed MBRs: treatability and cost. Water Sci. Technol. 80(4), 762-772. 
Park, S. H., Park, Y. G., Lim, J., Kim, S., 2015. Evaluation of ceramic membrane applications for water treatment plants with a life cycle cost analysis. Desalin. Water Treat., 54(4-5), 973-979.

Peters, M., Timmerhaus, K., 1991. Plant Design and Economics, McGraw Hill, NY.

UKDft, 2020. TAG unit A1-1 cost-benefit analysis, https://www.gov.uk/government/publications/webtag-tagunit-a1-1-cost-benefit-analysis-may-2018. Accessed 18/12/2020.

Yoo, S. S., Chu, K. H., Choi, I., Mang, J. S., Ko, K. B., 2018. Operating cost reduction of UF membrane filtration process for drinking water treatment attributed to chemical cleaning optimization. J. Environ. Manag. 206, 11261134.

Young T., Smoot S., Peeters J., Côté P., 2013. When does building an MBR make sense? How variations of local construction and operating cost parameters impact overall project economics, Proc. Water Env. Fed. 8, 6354-6365.

Zheng, X., Ernst, M., Jekel, M., 2011. Stabilizing the performance of ultrafiltration in filtering tertiary effluenttechnical choices and economic comparisons. J. Membrane Sci. 366(1-2), 82-91.

Zsirai, T., Buzatu, P., Aerts, P., \& Judd, S., 2012. Efficacy of relaxation, backflushing, chemical cleaning and clogging removal for an immersed hollow fibre membrane bioreactor. Water Res. 46(14), 4499-4507. 


\section{Appendix A Consumer price index CPI}

Historical information (Fig. A1) indicates the UK consumer price index to have followed a roughly linear trend with year $(y)$ since the turn of the millennium:

$$
\mathrm{CPI}=2.002 y-3933\left(\mathrm{R}^{2}=0.98\right)
$$

The CPI thus increased by roughly two units a year from a value of 71 from the year 2000 onwards, reaching 111 in the year 2020.

The CPI was used to correct the CAPEX component excluding the membrane module cost, which was determined from owner data to represent $\sim 25 \%$ of the cost of the membrane technology component cost. The 2020 capital cost $\left(L_{C}\right)$ thus correlates with the capital cost $L_{C, y}$ at year $y$ according to:

$$
\begin{aligned}
L_{C} & =111 \times 0.75 L_{C, y} /(111-2(2020-y))+0.25 L_{C, y} \\
& =83.3 L_{C, y} /(111-2(2020-y))+0.25 L_{C, y}
\end{aligned}
$$

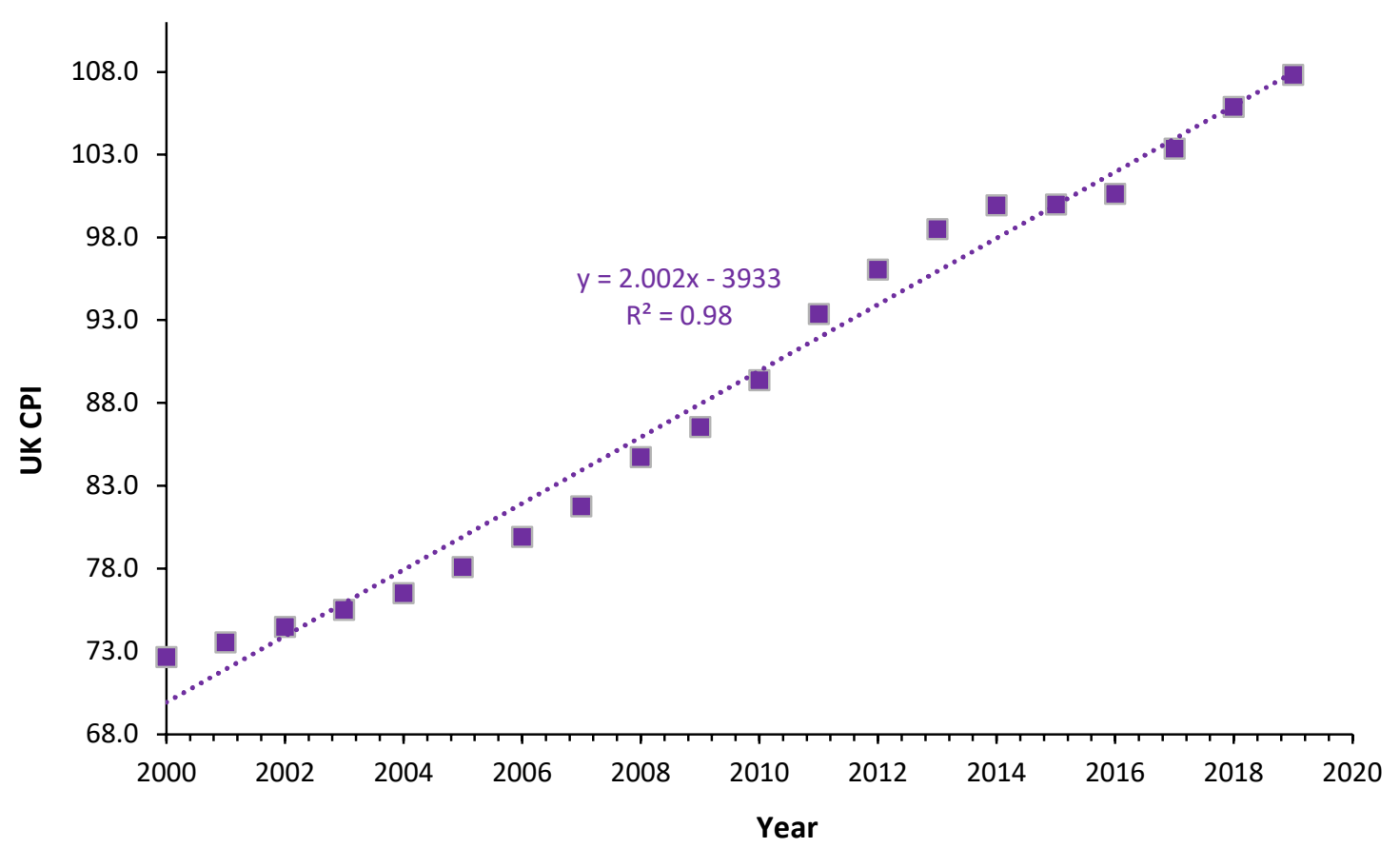

Figure A1: $\quad$ UK Consumer Price Index trend 


\section{Appendix B Liquid and air pumping energy}

\section{Liquid}

The energy demand for permeate pumping is approximately given by:

$$
E_{L}{ }_{L}=\left(P+P_{\text {losses }}\right) /\left(36 \varepsilon_{p} \theta\right)
$$

where $P$ is the average feed pressure in bar, $P_{\text {losses }}$ represent the system losses, $\varepsilon_{p}$ is the pump efficiency and $\theta$ is the conversion. This assumes that the liquid pumping energy consumed during the backflush cycle is approximately the same as for the filtration cycle. If $P$ is assumed to be 0.3 bar and the system losses add a further 0.05 bar, the pumping efficiency $70 \%$ and the conversion $95 \%$, then the energy consumed by liquid pumping is:

$$
E_{L}{ }^{\prime}=(0.3+0.05) /(3.6 \times 0.7 \times 0.95)=\mathbf{0 . 1 4 6} \mathbf{~} \mathbf{W h} / \mathbf{m}^{3}
$$

\section{Air}

Compressed air is used during the backwash cycle. The total energy consumed for air pumping per $\mathrm{m}^{3}$ permeate thus depends on the backwash frequency, the minimum value for this being 30 minutes.

The aeration energy consumption in $\mathrm{kWh} / \mathrm{Nm}^{3}$ air is given by:

$$
E_{A, \text { air }}^{\prime}=k\left((0.0987 h+1)^{0.283}-1\right) / \varepsilon_{b}
$$


where $k=0.102 \mathrm{kWh} / \mathrm{Nm}^{3}, h$ is the head of pressure in m water, and $\varepsilon_{b}$ the blower efficiency. For a maximum pressure of 10 bar (100 m head) and a blower efficiency of $70 \%$ :

$$
E_{A, \text { air }}=0.102 \times\left((0.0987 \times 100+1)^{0.283}-1\right) / 0.7=0.141 \mathrm{kWh} / \mathrm{Nm}^{3}
$$

The assumed air consumption rate is $2.5 \mathrm{Nm}^{3}$ for a minimum permeate volume of $1 \mathrm{ML}$, based on a backflush frequency of 30 minutes, equating to an energy consumption of $0.352 \mathrm{kWh}$. If this energy is expended for a minimum permeate volume of $1 \mathrm{ML}$, or $1000 \mathrm{~m}^{3}$, then the maximum specific energy consumption for air pumping per $\mathrm{m}^{3}$ permeate is:

$$
E_{A, \text { permeate }}=E_{A}{ }^{\prime}=0.352 / 1000=\mathbf{0 . 0 0 0 3 5 2} \mathbf{~ k W h} / \mathbf{m}^{3}
$$

The energy expended for air pumping is thus negligible. 


\section{Appendix C Chemical cleaning}

\section{Chemical cleaning reagent consumption}

The chemical reagents used for the cleaning in place (CIP) are sodium hypochlorite $(\mathrm{NaOCl})$, caustic soda $(\mathrm{NaOH})$, sulphuric acid $\left(\mathrm{H}_{2} \mathrm{SO}_{4}\right)$, and citric acid (CA) (Table $\left.\mathrm{C} 1\right)$. Data used to calculate the specific cost for chemicals supply are indicated below for a 30d CIP interval. The chemical consumption cost for either a hypochlorite or caustic soda based clean, in both cases with supplementary mineral/citric acid cleaning, is therefore roughly given by:

$$
L_{R}{ }_{R}, £ / \mathrm{m}^{3}=0.22 \times 10^{-3} \times 30 / t_{C I P}
$$

where $t_{C I P}$ is the interval between CIPs used in practice, normally at least $28 \mathrm{~d}$ unless there is a clogging event, such that for a 30-day cleaning interval $\boldsymbol{E}_{\boldsymbol{R}} \sim \mathbf{£ 0 . 0 0 0 2 2}$ per $\mathrm{m}^{3}$ permeate for a hypochlorite or caustic soda based CIP.

Table C1: Costs, based on 30 d CIP interval

\begin{tabular}{l|cccc}
\hline Reagent & Concentration & $\begin{array}{c}\text { Demand } \\
\text { L/ML }\end{array}$ & $\begin{array}{c}\text { Supply cost } \\
£ / L \text { reag }\end{array}$ & $\begin{array}{c}\text { Specific cost } \\
£ / M L\end{array}$ \\
\hline $\mathrm{NaOCl}$ & $10 \%$ & 0.15 & $£ 0.60$ & $£ 0.1080$ \\
$\mathrm{NaOH}$ & $32 \%$ & 0.12 & $£ 0.63$ & $£ 0.0905$ \\
$\mathrm{H}_{2} \mathrm{SO}_{4}$ & $50 \%$ & 0.08 & $£ 0.45$ & $£ 0.0432$ \\
$\mathrm{Citric} \mathrm{A}$ & $50 \%$ & 0.067 & $£ 0.90$ & $£ 0.0720$ \\
\hline
\end{tabular}

\section{Chemical cleaning liquid heating}

CIPs are usually conducted using cleanants heated to $30-35^{\circ} \mathrm{C}$, incurring an additional cost penalty to the reagent consumption. For a temperature change of $\Delta \mathrm{T}$, a specific heat capacity of $\mathrm{C}_{\mathrm{p}}$, a total CIP liquid volume of $V_{C I P}$, a heating efficiency of $\varepsilon_{h}$, and proportional heat losses of $\varepsilon$, the heating energy, then: 


$$
E^{\prime}{ }_{H}=\Delta \mathrm{T} \mathrm{C}_{\mathrm{p}} V_{C I P} /\left(t_{C I P} \varepsilon_{h}\left(1-\varepsilon_{l}\right)\right)
$$

Baseline values used (Table C2) imply a $E^{\prime}{ }_{H}$ value of $\mathbf{0 . 0 0 1 0} \mathbf{k W h} / \mathbf{m}^{3}$ for a typical $30 \mathrm{~d}$ CIP interval, increasing to $\mathbf{0 . 0 0 8 6} \mathbf{~} \mathbf{W h} / \mathbf{m}^{3}$ for a $3.5 \mathrm{~d}$ interval, as may be expected during a severe clogging event. Severe clogging thus adds $\sim 6 \%$ to the energy consumption.

Table C2: Baseline values, CIP reagent liquid chemicals heating

\begin{tabular}{l|c}
\hline Parameter & Value \\
\hline Maximum temperature change $\Delta \mathrm{T}_{\max },{ }^{\circ} \mathrm{C}$ & 25 \\
Specific heat capacity, $\mathrm{C}_{\mathrm{p}}, \mathrm{kJ} /{ }^{\circ} \mathrm{C} / \mathrm{kg}$ & 4.2 \\
Volume of cleaning liquid, $V_{C I P} / Q, \mathrm{~m}^{3}$ per $1,000 \mathrm{~m}^{3} / \mathrm{d}$ flow & 0.5 \\
Heat efficiency, $\varepsilon_{h}$ & $60 \%$ \\
Losses, $\varepsilon_{l}$ & $20 \%$ \\
Interval, d & 30 \\
\hline E $\mathbf{k W h} /$ (CIP-Q) & $\mathbf{0 . 0 0 1 0 1}$ \\
\hline
\end{tabular}




\section{Appendix D Critical component replacement}

The membrane module represents the most significant critical component in terms of OPEX.

The averaged specific cost for membrane replacement $L^{\prime}{ }_{M}$ in $£ / \mathrm{m}^{3}$, ignoring discounting and inflation, is given by the membrane cost per $\mathrm{m}^{2}\left(L_{M}\right)$, the flux $J$ in $\mathrm{L} /\left(\mathrm{m}^{2} . \mathrm{h}\right)$ and the membrane life $t_{M}$ in years (Table D1)

$$
L^{\prime}{ }_{M}, £ / \mathrm{m}^{3}=1000 L_{M} /\left(J t_{M} \times 365 \times 24\right)=0.114 L_{M} /\left(J t_{M}\right)
$$

Table D1: Example membrane costs

\begin{tabular}{l|ccccc}
\hline Technology & Area, $m^{2}$ & $L_{M}, £ / m^{2}$ & $J, L M H$ & $t_{m}, y$ & $L^{\prime}, £ / m^{3}$ \\
\hline HFla & 23.4 & $£ 27.78$ & $61-76$ & 7 & $0.0060-0.0074$ \\
HF1b & 34.8 & $£ 24.43$ & 41 & $7-8$ & $0.0054-0.0089$ \\
HF1c & 34.5 & $£ 18.84$ & $61-62$ & $5-8$ & $0.0065-0.011$ \\
HF2 & 50 & $£ 25.00$ & $69-97$ & 10 & $0.0024-0.0027$ \\
CT & 40 & $£ 60.00$ & $100-110$ & 10 & 0.0065 \\
\hline \multicolumn{7}{l}{ HFla-HFlc: these products refer to different models from the same technology supplier $(H F 1)$}
\end{tabular}

Based on a fairly conservative flux of $45 \mathrm{LMH}$, a cost of $£ 25 / \mathrm{m}^{2}$, and a life of $7 \mathrm{y}$, an undiscounted cost of $\mathbf{E 0 . 0 0 9 1}$ per $\mathbf{m}^{3}$ permeate can be assigned to membrane replacement. 